\title{
Bimodality In Interim Reports: An Analysts' View
}

Hannu A. Kahra, (E-mail: hannu.kahra@sofi.fi), Turku School of Economics and Business Admin., Finland Antti J. Kanto, (E-mail: kanto@hkkk.fi), Helsinki School of Economics, Finland

Hannu J. Schadewitz, (E-mail: Hannu.Schadewitz@tukkk.fi), Turku School of Economics and Business Admin., Finland Dallas R. Blevins, (E-mail: blevins@montevallo.edu), University of Montevallo

\begin{abstract}
Cumulative abnormal residuals (cars) show how markets adjust to published information. Theoretically, cars are assumed to display unit normal behavior. Despite its merits, car has proved to be a somewhat imprecise measure of market response to published information. In practice, cars exhibit considerable deviation from theoretical unit normal behavior. Three disparities between theory and practice can be pinpointed. These are car: (1) location, (2) shape, and (3) stability. In our previous work we have demonstrated that cars are often bimodally distributed. This finding shows one reason why it takes semistrong efficient markets some time to digest new information. Cars, for the time period during which markets analyze the new value determining data, are usually bimodally distributed. One mode of the distribution represents the impact of good news. The other peak is caused by bad news. The valley, between the two peaks, indicates the influence of neutral news. This paper analyzes the interim reports, which constitute the data for our previous related studies. This research identifies the type of new information that creates bimodal cars.
\end{abstract}

\section{Introduction}

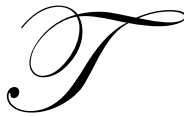

his article is a continuation of a series of works designed to help answer three questions about the disparity between theory and practice vis-à-vis cumulative abnormal residuals (cars). These three questions are car: (1) location, (2) shape, and (3) heteroscedasticity. Recent research: (1) lays a theoretical foundation for the answer to the three questions (Kanto, Kahra, Blevins, \& Schadewitz 1998) and (2) provides empircal evidence supporting these answers (Kahra, Kanto, Schadewitz, \& Blevins 2001, 2004). The model used in previous studies to make the examination is so labor and capital intensive that its use is, from a practical standpoint, limited to major: (1) firms, (2) investment houses, and (3) universities. Because the authors believe that research should provide an ultimate benefit to society, this article is constructed in an attempt to make the findings of practical use. The interim reports, which constitute the data for the three studies mentioned above, are analyzed to show the type of new information that creates bimodal cars. Thus, application of the findings can be immediately applied, though not with the precision desired. Subsequent research must be relied upon for that, but this article is a beginning place.

\section{Background}

This section addresses the recent history of the search for a solution to the reason(s) for the disparity between theory and practice vis-à-vis the: (1) location of cumulative abnormal residuals (cars), (2) shape of cars and (3) heteroscedasticity of cars.

\section{Location and Shape}

For more than three decades, investors have puzzled over the inability of academics to describe the behavior of cumulative abnormal residuals (cars). Theoretically, cars are assumed to display unit normal behavior. Empirically, however, cars are often observed to display two major departures from unit normal behavior. One, the 
residuals are often not centered at "zero." Two, they are often much flatter than normal or $t$ distributions would predict. The authors believe one answer to the disparity between theory and practice is that a bell shaped model is exclusively used to: (1) forecast the shape of cars (theory) and (2) measure the shape of cars (practice). The authors believe this model is too restrictive. The error term is sometimes bell shaped but not exclusively so. Sometime the distribution of the residual term is skewed, and sometimes it is bimodal.

In 1998, Kanto, Kahra, Blevins, and Schadewitz state their believe that the cars might take any of several shapes: (1) unit normal, (2) $t$, (3) positive skew, (4) negative skew, or (5) bimodal. The bimodal case, in turn, could have equal modes, a larger left mode or a larger right mode. If the distributions that are measured by a unit normal or $t$ distribution are actually skewed or even bimodal, then both anomalies (the non-zero location and the flatter than expected shape) would be, in some part, answered.

In 2001, Kahra, Kanto, Schadewitz, and Blevins test this theory using a model that allows cars that are: (1) normal, (2) $t$, (3) skewed (either way) and (4) bimodal (with equal or unequal modes). Interim reports, submitted to the Helsinki Exchanges (HE) over the period 1985-93, provide the sample data. The study focuses on the existence of bimodality. The findings show that bimodality exists.

Kahra, Kanto, Schadewitz, and Blevins further examine car bimodality in 2004. This most recent research demonstrates that it is not uncommon for value-determining new information to generate bimodal cars. During the examination period, there are just 62 non-insurance/non-financial institution sector firms reporting to the HE. Of this number, 48 (77.4 percent) submit such ambivalent information creating at least one bimodal car. Since firms enter and leave organized exchanges each year, a year-by-year analysis of bimodality is also conducted. The average bimodality, by firm and year is 52.7 percent, with the smallest proportion being 0.355 . Never fewer-than one-third of the firms report information that creates such confusion among investors that a bimodal car results. Overall, results show that bimodality is a relatively common phenomenon.

\section{Heteroscedasticity}

Another theoretical problem is the existence of a varying standard deviation among the cars. Theory argues that residuals should have a fixed standard deviation, but in practice this is not usually occurring. Further, postannouncement drift (a certain delay in the market's adjustment to published earnings information) should not exist. Even if it does, the cars should be homoscedastic. Kanto, Kahra, Blevins, and Schadewitz (1998) argue that the value determining new information extant in interim reports might take some time to digest, thus explaining the existence of post-announcement drift (see also Schadewitz and Kanto, 2002). Further, they argue that, if the new information is partly share price enhancing and partly share price diminishing, the distribution of $c a r$ will be skewed or bimodal, as opposed to unit normal or $t$ distributed. Even further, since it takes some time for the market to correctly interpret the value determining signals, the distribution of car will be changing shape and position as the consensus is being reached.

Kahra, Kanto, Schadewitz, \& Blevins (2001) find empirical evidence that, at the bimodal extreme, the HE demonstrates a heteroscedastic tendency when new value determining information is partly favorable and partly unfavorable. Further analysis of this prospect is made the Kahra, Kanto, Schadewitz, \& Blevins (2004) work.

The next section makes the first practical application of these findings.

\section{Analyses}

One example of all 48 of the possible 62 bimodal firms is presented below. The expectation is that analysts will see, almost immediately, the pattern that is extant in these dualistic reports. Unfortunately, the authors are not yet able to suggest anything other than the subjective existence of bimodality. This information, alone, however, is of value to the financial analyst. There is a link between the words presented in interim reports, summarized below, and bimodality, with its post-announcement drift (Kothari, 2001). This has important practical implications. 
Our analyses proceed as follows. Based on the statistical analyses, we identify the most bimodal day for each of the 48 bimodal firms. Selection of these firm-specific high bimodal cases is based on quantitative data that are not discussed here. After selection, a qualitative analysis, based on interim report content follows. Then, our analysis focuses on bimodal days for each of the 48 firms listed in the appendix.

After discovering the most and least bimodal case for each bimodal firm we use well known analyst tools to investigate the nature of the bimodality exhibited in each of the 48 firms. In section "Persistence of and explanations for bimodality", we focus on the length of time it takes the market to resolve each bimodal report. Since our qualitative findings are extracted directly from the first-hand communication data published by the firms themselves, analysts should be able to use new publicly available information the same way. This protocol also helps discover the existence of patterns in the resolution of market uncertainty (indicated by bimodality). This, in turn, could help reporting managers improve their efforts to communicate value determining information to the markets.

\section{Overall existence of bimodality}

Number of interim reports causing bimodality. The table shows number of all interim reports in the sample (411 interim reports). Further, it shows how those reports are published in industry lines. Numerator indicates the number of reports causing at least one bimodal day within 10 days return window after the publication. Denumerator shows all published interim reports in a particular shell. Index is direct outcome of this division.

Table 1 The number of interim reports causing bimodality according to years and industries

\begin{tabular}{|c|c|c|c|c|c|c|c|c|c|c|}
\hline Industry Year: & -85 & -86 & -87 & -88 & -89 & -90 & -91 & -92 & -93 & Total \\
\hline \multirow[t]{2}{*}{ 1. Transport } & - & 100 & 50 & 0 & 0 & 50 & 40 & 60 & 75 & 48 \\
\hline & $0 / 0$ & $2 / 2$ & $1 / 2$ & $0 / 2$ & $0 / 3$ & $2 / 4$ & $2 / 5$ & $3 / 5$ & $3 / 4$ & $13 / 27$ \\
\hline \multirow[t]{2}{*}{ 2. Trade } & 100 & 40 & 60 & 20 & 62 & 29 & 33 & 75 & 50 & 48 \\
\hline & $2 / 2$ & $2 / 5$ & $3 / 5$ & $1 / 5$ & $5 / 8$ & $2 / 7$ & $2 / 6$ & $3 / 4$ & $1 / 2$ & $21 / 44$ \\
\hline \multirow[t]{2}{*}{ 3. Other services } & - & 0 & 50 & 100 & 40 & 0 & 0 & 0 & 75 & 26 \\
\hline & $0 / 0$ & $0 / 3$ & $1 / 2$ & $3 / 3$ & $2 / 5$ & $0 / 3$ & $0 / 7$ & $0 / 7$ & $3 / 4$ & $9 / 34$ \\
\hline \multirow{2}{*}{$\begin{array}{l}\text { 4. Metal and } \\
\text { engineering }\end{array}$} & 33 & 0 & 0 & 0 & 43 & 40 & 50 & 75 & 71 & 44 \\
\hline & $1 / 3$ & $0 / 3$ & $0 / 3$ & $0 / 3$ & $3 / 7$ & $4 / 10$ & $4 / 8$ & $6 / 8$ & $5 / 7$ & $23 / 52$ \\
\hline \multirow[t]{2}{*}{ 5. Forest industry } & 0 & 25 & 50 & 33 & 14 & 33 & 60 & 50 & 100 & 40 \\
\hline & $0 / 2$ & $1 / 4$ & $4 / 8$ & $3 / 9$ & $1 / 7$ & $2 / 6$ & $3 / 5$ & $2 / 4$ & $3 / 3$ & $19 / 48$ \\
\hline \multirow[t]{2}{*}{ 6. Food industry } & - & - & - & - & 50 & 0 & 0 & 0 & 0 & 17 \\
\hline & $0 / 0$ & $0 / 0$ & $0 / 0$ & $0 / 0$ & $1 / 2$ & $0 / 1$ & $0 / 1$ & $0 / 1$ & $0 / 1$ & $1 / 6$ \\
\hline \multirow{2}{*}{$\begin{array}{l}\text { 7. Telecom. and } \\
\text { electronics }\end{array}$} & - & 0 & 0 & 0 & 50 & 50 & 100 & 100 & 100 & 50 \\
\hline & $0 / 0$ & $0 / 2$ & $0 / 2$ & $0 / 2$ & $1 / 2$ & $1 / 2$ & $2 / 2$ & $2 / 2$ & $2 / 2$ & $8 / 16$ \\
\hline \multirow{2}{*}{$\begin{array}{l}\text { 8. Media and } \\
\text { publishing }\end{array}$} & 100 & 50 & 100 & 50 & 0 & 25 & 0 & 0 & 0 & 32 \\
\hline & $1 / 1$ & $1 / 2$ & $2 / 2$ & $1 / 2$ & $0 / 2$ & $1 / 4$ & $0 / 2$ & $0 / 2$ & $0 / 2$ & $6 / 19$ \\
\hline \multirow[t]{2}{*}{ 9. Other industries } & 100 & 100 & 43 & 62 & 55 & 40 & 60 & 58 & 89 & 62 \\
\hline & $2 / 2$ & $3 / 3$ & $3 / 7$ & $5 / 8$ & $5 / 9$ & $4 / 10$ & $6 / 10$ & $7 / 12$ & $8 / 9$ & $43 / 70$ \\
\hline \multirow[t]{2}{*}{ 10. Multi- business } & - & 33 & 0 & 0 & 50 & 50 & 50 & 60 & 100 & 45 \\
\hline & $0 / 0$ & $1 / 3$ & $0 / 3$ & $0 / 4$ & $2 / 4$ & $2 / 4$ & $2 / 4$ & $3 / 5$ & $4 / 4$ & $14 / 31$ \\
\hline \multirow[t]{2}{*}{ 11. Industry } & 80 & 62 & 62 & 25 & 60 & 37 & 17 & 33 & 40 & 47 \\
\hline & $4 / 5$ & $5 / 8$ & $5 / 8$ & $2 / 8$ & $6 / 10$ & $3 / 8$ & $1 / 6$ & $2 / 6$ & $2 / 5$ & $30 / 64$ \\
\hline \multirow[t]{2}{*}{ Total } & 67 & 43 & 45 & 33 & 44 & 36 & 39 & 50 & 72 & 45 \\
\hline & $10 / 15$ & $15 / 35$ & $19 / 42$ & $15 / 46$ & $26 / 59$ & $21 / 59$ & $22 / 56$ & $28 / 56$ & $31 / 43$ & $187 / 411$ \\
\hline
\end{tabular}


First line in each industry shows indexed (=ratio*100) result for the ratio: (the number of interim reports published in that industry and year causing bimodality)/(the number of all interim reports in that industry and year included in the sample). Second line in each industry and in each year shows ratio: (the number of interim reports published in that industry and year causing bimodality)/(the number of all interim reports in that industry and year included in the sample).

Based on table 1 above we can identify general patterns about the existence of bimodality through time and industry lines. In general we can see that interim reports are often causing bimodality to the market. Table shows (shell: Total, Total) that the total number of published interim reports in the sample is $411.45 \%$ of these published interim reports (187 reports) caused bimodality to the market. In other words in 187 cases market participants were not sure about the overall direction of the news (bad news, neural news, or good news) communicated in those reports.

Table 1 shows also that bimodality is relatively common phenomenon also through industries. Business sector 9. Other industries receives highest total frequency percentage $62 \%$, where 43 interim reports of total 70 interim reports caused bimodal return behavior to the market. In terms of business classification Other industries can be seen as residual industry class, i.e. a class containing firms that do not belong to some other, more common or general industry. A firm's belonging to Other industries class as such could have caused markets some difficulties to digest the information and its direction disclosed in interim reports. This, in turns, could have caused the high frequency of bimodal return behavior at and after the event. We also studied where the bimodality was at the lowest. Industry 3. Other services received the lowest bimodality figures, only $26 \%$. Due to the low number of firms in this sector, only three, could give possibilities market participants to know those firms relatively well. The potential familiarity with the firms, in turn, could have helped markets to figure out relatively well these firms' performance and future prospects (low bimodality). More detailed, firm-specific discussion will follow in the next section. Also industry 8. Media and publishing is linked with low bimodality. There are only two firms in this business class, so markets could well be familiar with these firms, which, in turn, can result to low bimodality. Firm- and interim report- specific discussions will offer additional insight to these observations later in the text.

Table 1 shows also how bimodality exists through years. Index figures in row Total shows that high frequency of bimodality occurred in years 1985 (67), 1992 (50) and 1993 (72). The development of the generalindex of the Helsinki Stock Exchange (HE) gives additional insight to these bimodality frequencies. Table 2 below displays the relationship of the HE generalindex and the number of interim reports causing bimodality.

Table 2. The relationship of the HE generalindex and the number of bimodal firms

\begin{tabular}{lcc|ccc}
\hline Year & Generalindex & Change $(\%)$ & $\begin{array}{l}\text { \# of bimodal } \\
\text { interim reports }\end{array}$ & $\begin{array}{l}\text { \% of bimodal } \\
\text { interim reports }\end{array}$ & Change (\%) \\
\hline 1985 & na & $5.7 \%^{\mathrm{a}}$ & 10 & $66.7 \%$ & $-3 \%$ \\
1986 & na & $62.9^{\mathrm{a}}$ & 15 & 42.8 & 5.6 \\
1987 & 1318.39 & 27.8 & 19 & 45.2 & -27.9 \\
1988 & 1829.98 & 38.8 & 15 & 32.6 & 35.3 \\
1989 & 1533.05 & -16.2 & 26 & 34.1 & -19.3 \\
1990 & 1000.00 & -34.8 & 21 & 39.3 & 10.4 \\
1991 & 781.84 & -21.8 & 28 & 50.0 & 27.2 \\
1992 & 829.00 & 6.0 & 31 & 72.1 & 44.2 \\
1993 & 1582.12 & 90.8 & & & \\
1994 & 846.59 & 16.7 & & & \\
\hline
\end{tabular}

$n a=$ not available.

${ }^{\text {a }}$ Change (\%) in years 1985 and 1986 is based on KOP index.

Source: HE annual report 1989, 1993 and 1994

Table 2 shows high bimodality in year 1985. One potential explanation is that firms were anticipating the first major step in the development of interim financial regulation. In January 1, 1986 (effective date) a 
recommendation concerning interim financial statements was given (HSE Cooperative, 1988, p. 18). High bimodality in 1985 could well be because of this new, unestablished, practice. For example there could be heterogeneous reporting practices in interim reports during the early phase of their development. Also the attempts to anticipate the positive development of share markets may have caused increased bimodality especially in 1985 .

Table 2 shows also another peak in the frequency of bimodality. That occurs in years 1992-1993. At that time interim reporting was already well-established practice as part of the Helsinki Stock Exchange listed firms communication. Reason for bimodality in years 1992-1993 can be addressed to the bullish market development. For example increase in the generalindex in year 1993 was $90.8 \%$. Market's attempts to anticipate more specific time for this development could well have been caused bimodality. Firm and report specific analyses later will give additional and more specific insight to these general conclusions.

\section{Persistence of and explanations for bimodality}

This section studies observed bimodality in more details. Qualitative we try to find out some potential patterns in the bimodal behavior. We have already seen that year as well as industry are related to the frequency of bimodality. This section tries to deepen these overall findings by examining the content of actual interim reports that have caused bimodal return behavior. Characterization of bimodality is discusses and also types of information that have caused bimodality are presented. Disclosed information is classified into favorable and unfavorable indicators and analyzed accordingly. This section will proceed as follows. First we present the Industry with the highest relatively frequency of bimodality (Table 1. Sector 9. Other industries) and then Industries with the lowest relatively frequency of bimodality (Table 1 . Sector 3 . Other services and sector 8 . Media and publishing).

We start the detailed analysis from 9. Other industries which has the highest bimodal frequency. 43 out of 70 interim reports $(61.4 \%)$ are causing bimodal return distribution. Amer has 9 interim reports during the research period. 6 of the reports caused bimodality to the market (66.6\%). Typically for Amer days 0 through 4 are bimodal. In other words, it take markets about five days to digest the information content of published interim report. The content analysis of Amer's interim reports reveals some of the reasons for the bimodality. For example interim report Mar-Aug 1989 contains following favorable indicators: large mergers into new branches, the expansion of brands into its product portfolio, and the stock purchase of Wilson Sporting Goods Co. All in all the disclosed information indicates that Amer is heavily involved in internationalization process. Unfavorable information is economic recession, with bearish expectations for the Helsinki Stock Exchange. Analysts could well recognize the uncertainties to the internationalization process. Uncertainty is increased due to the bearish expectations in the market. Together these uncertainties related with favorable and unfavorable indicators are logical reasons for bimodal return behavior.

Finvest is another typical example of 9. Other industries category firm. It has several industries from different areas covering production of condensers, other precision mechanical components, and depository banking. Typically also here days 0 through 4 are bimodal. Half of the interim reports ( 4 out of 8 ) cause bimodal return distribution. Favorable indicator in Finvest Jan-Jun 1993 report is the decrease in loss compared to previous year. Unfavorable indicator is that the firm reports continuing negative earnings. Also market situation for various businesses is said to be heterogeneous. The multidimensional nature of is very logical reason for market uncertainty regarding Finvest, especially because the structure of the firm is recently established.

Tampella and Raision Tehtaat are examples of 9. Other industries firms that have high frequency of bimodality that last usually days 0 through 8 . Tampella has bimodality that sometimes lasts even the whole examination window (days 0 through 10), e.g. of this is Tampella Jan - Aug 1990 interim report. This report contains unfavorable news regarding the market situation as a whole. Report also contains information about the heavy adjustment of operations and organizational structures as a response to the changed market situation. Bimodality in the markets could well be addresses to the possibilities of these actions to improve firm's performance. Tampella Jan-Aug 1988 report discloses favorable indicators as follows. First, it indicates that a large investment program is launched. Further, the overall development and future prospects of business lines are said to be favorable. Finally, Tampella has a strong initiative to internationalize its operations via acquisitions. Unfavorable 
indicator is that prices in the cardboard industry are said to be unsatisfactory. Raision Tehtaat Jan-Jun 1993 reports as a favorable signal that prospects for improved earnings development are anticipated. Unfavorable signal for Raision Tehtaat is a severe drop in earnings compared to previous year.

Compared to previous firms Tamfelt and Suomen Trikoo represent a somewhat different bimodality persistence among 9. Other industries category. Tamfelt and Suomen Trikoo had typically only one bimodal day during the time 0 through 10 days. Further 11 out of 12 reports for Tamfelt and 6 out of 7 reports for Suomen Trikoo caused bimodal behavior. In addition, it should be mentioned that the bimodal day is normally eight day after the event for both Tamfelt and Suomen Trikoo. This suggests that markets have some uncertainty for those firms but it is resolved during the examination window. Tamfelt reports simultaneously an increase in orders and an underutilization of capacity. Suomen Trikoo reports new cooperation activities in Sweden and in Estonia and decrease in earnings.

The other extreme in the bimodality continuum is 3 . Other services, where the overall frequency of bimodality is the lowest. 9 out of 34 interim reports (26.5\%) caused bimodal behavior. Here the bimodality is typically related to only one interim report and bimodality lasts several days. Tietotehdas Oct 1987 - Mar 1988 interim report caused 10 days bimodal return period. Favorable information disclosed is that Tietotehdas has acquired a majority of Datema. At that time Datema was the largest data-service and data-programming firm in the Nordic countries. According to the interim report, Tietotehdas gains a strong market position. Unfavorable indicator in the interim report is that the future of computer business is said to be uncertain as a whole. Lassila \& Tikanoja Jan - Aug 1993 report causes some bimodality at the latter part of the investigation window (days 6, 7 and 10). Favorable indicator is that firm's exceptional investment project had been successful. Unfavorable indicator is that the firm has experienced a drop in earnings - one business line is performing worse than in the previous year.

Sector 8. Media and publishing industry has also low bimodality. One likely reason is that both firms in this category, Otava and WSOY, are well-established, traditional and widely known firms. Both firms have few bimodal days at the end portion of the examination window. Usually those bimodalities are only one day. Otava Jan-Aug 1987 report discloses, as a favorable news, an increase in the operating profits and improved operational efficiency. In the same report the unfavorable news is a drop in sales volume. Bimodality is likely due to the uncertainty regarding the permanency of sales volume decrease, especially because there is neither explanation for the causes of the sales drop nor detailed future actions due to the sales drop.

After discussing the most bimodal and least bimodal industries above we will discuss the rest of the industries below.

Sector 1. Transport had 13 interim reports out of 27 causing bimodal return distribution (48.1\%). Effoa Jan - Aug 1990 reports favorable news regarding the increase in the number of passengers. Further there is information of merger between Effoa and Johnson Lines. Unfavorable news are as follows. First, a large portion of Effoa's income comes from personal traffic. The economic recession in Finland causes people to reduce their spending on leisure traveling. The interim report explicitly details overcapacity available on the market. Yet, the firm is waiting for a new, large capacity vessel to be ready for its route. It should be mentioned that all interim reports after this Jan - Aug 1990 report causes bimodal return distribution. This support strongly the view that market participants have relatively stable twofold expectations regarding Effoa. Finnlines is another Transport firm. Its interim report Jan Aug 1993 reports a large increase in earnings as a favorable news. Unfavorable news indicates that there is a national imbalance between import and export sea freight. Further, the domestic purchasing power is weakened causing reductions in imports.

Sector 2. Trade had 21 interim reports out of 44 causing bimodal return distribution (47.7\%). Among interim reports causing bimodality in this industry are Kesko Jan - Aug 1992 and Stockmann Jan - Jun 1993. Favorable indicator for Kesko is success in its cost control efforts. Stockmann discloses increase in sales. Unfavorable news that Kesko discloses is that its earnings are anticipated to be at the same level than previous year. Stockmann discloses that the level of national consumption will decrease. For Kesko the bimodality is resolved during the examination window. Contrary to that, for Stockmann the bimodality stays for the whole examination 
window. This may be due to primary reaction for recession. Kesko indicates that its cost control efforts have been successful. Stockmann discloses about the reduction in anticipated consumption but without detailed explanation how it will react to the changing market situation.

Sector 4. Metal and engineering contains large and well established firms. 23 interim reports out of 52 caused bimodal return distribution (44.2\%). Usually these firms have several business lines. Typical case in interim report causing bimodal return distribution is that some business segments indicates satisfactory results and some others unsatisfactory results. It is normal that bimodality exists for the most of the examination window. Outokumpu Jan - Apr 1991 reports as a favorable news that the results of the steel segment have been satisfactory. Unfavorable indicator is that the result of all other segments have been unsatisfactory. Valmet reports similar types of news in its Jan - Aug 1993 interim report. Favorable indicator is improvement in overall performance and unfavorable news is that one business line continued to produce losses. The bimodal days for Valmet Jan - Aug 1993 report are 2, 3, 4, and 7. A special case in this industry group is Wärtsilä, where former administration has been sued by the shareholders.

Sector 5. Forest industry is traditional in Finland and can be classified as a heavy industry. Typically the bimodality stays several days but is resolved within the examination window. Metsä-Serla Jan - Aug 1993 interim report causes days $0,1-4,6-7$, and 10 to be bimodal. Favorable news in that report are related to the positive results that exceeded the budget. Unfavorable news indicate that demand is slowing down.

Sector 6. Food industry had only one interim report out of 6 causing bimodal return distribution after the event (16.7\%). Firm Liha-Polar is recently listed (Aug 1988). Shortly after its listing Liha-Polar's interim report caused bimodal behavior to the market (Jan - Apr 1989 interim report).The report as such is very brief. It describes briefly the increased growth compared to previous year. Further, interim report explains new production facility.

Sector 7. Telecommunication and electronics comprises Nokia. 8 out of 16 interim reports caused bimodal market behavior (50.0\%). Practically all interim reports published during 1990s cause this pattern. Nokia Jan - Aug 1991 contains favorable and unfavorable indicators. Favorable indicator highlights stronger financial structure, unfavorable indicator points out the high uncertainty in Nokia's major market areas.

Sector 10. Multi-business was also bimodal during 1990s. 14 out of 31 interim reports caused bimodal return distribution (45.2\%). Typically bimodality exists several days but disappears before the end of the examination window. Logical explanation is that it will take markets several days to digest all the new information published in multi-business context. In Partek Jan - Aug 1993 interim report days 0-9 have bimodal distribution. Favorable indicator in that report is prospects for improved operational results during the rest of the year. Unfavorable indicator anticipates that the recession in Europe will continue.

Sector 11. Industry contains manufacturing and production companies. 30 interim reports out of 64 caused bimodal return distribution (46.9\%). During 1980s Instrumentarium has one or two bimodal days per interim report. Usually four months interim report causes one bimodal day and eight months interim report causes two bimodal days. Instrumentarium Jan - Aug 1986 discloses favorable indicator that a share issue was successful. In addition, the sales for both patient monitors and professional kitchen equipment were increasing. Unfavorable news is a heavy drop in export of hospital equipment to the Russia. Another typical case with Industry category is Repola. Its interim report Jan - Aug 1993 causes long bimodality (days 0 through 8). Favorable interim report news is the noticeable improvement in earnings. Further, good demand in North America and Asia are believed to continue. Unfavorable indicator is that the current and anticipated future demand in Western Europe is low. Category 11. Industry have both short and long term bimodalities. Even same kind of reasons causes short bimodality for one firm and long bimodality for another firm. To recognize these differences could help analysts to profile each firm's security behavior at and after the event.

In this section we have discussed about the information in interim reports being linked to the bimodal return behavior at and after the event. At the beginning we focused to the most and least bimodal cases, 9. Other industries and 3. Other services, and 8. Media and publishing, respectively. For each Industry we selected few 
representative firms and interim reports and analyzed the content of those reports. This analysis was qualitative and focused on favorable and unfavorable indicators disclosed in a particular interim report. After the presentation of these high and low bimodality industries we went through the rest of the industries in the order displayed in Table 1 above.

Detailed analyzes did not give one single explanation for bimodal return behavior after the event. However, several interesting and important patterns were found. We believe that it is important for analysts to pay attention to these and similar type of regularities when performing their evaluation of a firm. Bimodality represents potentially a possibility to make a profitable investment and should therefore be of interest for analysts.

Persistence of bimodality varied a lot, from one day to 11 days. Short period of bimodality was typical for firms in 9. Other industries. Fundamentally the disclosed news in those reports were not very radical. Rather, bimodality was rather due to the simultaneous effects of positive and negative news. Characteristics of those news were that they were fairly closely connected to a firm's core operations.

For some firms bimodality stayed for the whole investigation window (11 days). Tampella was an example of this. Report causing rather permanent bimodality contained unfavorable news regarding the market situation as a whole. Further, report described also information about the heavy adjustment of operations and organizational structures as a response to the changed market situation.

Typically for established, well known firms the bimodality started from the beginning of the examination window and stayed some days, for example bimodality during days 0 through 6 is typical. After that the bimodality disappears. This finding support the view that active analysts can benefit from the disappearing of bimodality if they will react rapid enough to the favorable and unfavorable news disclosed in interim reports.

Finally it should be mentioned that economic recession times, such as in 1989 and 1990, increased the frequency of bimodal returns through several industries. In 1990s the bimodality was more common phenomenon than in 1980s.

\section{Summary and conclusions}

Cumulative abnormal residuals (cars) show how markets adjust to published information. Despite its merits, car has proved to be a somewhat imprecise measure of market response to published information. In practice, cars exhibit considerable deviation from theoretical unit normal behavior. Our paper focused on bimodal return distributions after the event which is the publication an interim report. One mode of the distribution represents the impact of good news. The other peak is caused by bad news. The valley, between the two peaks, indicates the influence of neutral news.

This research identifies the type of new information that creates bimodal cars. First we investigate in which years bimodal cars exists. That could give us some information how general economic phase influence to the existence of bimodal cars. Another dimension in our overall investigation was industry. We classified firms into 11 different industry classes and examined bimodal cars in each of those classes. The third phase was study interim reports that caused bimodal cars to the market. This was performed using original interim reports (total number of reports was 411). A representative interim report for each firm was selected. Information in those reports was classified into favorable and unfavorable indicators. We followed outsider's view, such as an analysts, in our evaluation.

Overall, the obtained results based on interim reports gave logical explanations for bimodality. The findings also support the ex ante anticipations about the impact of published information to the market. At this stage, we did not found out a single, most dominant, reason for bimodality. However, data support several reasons for bimodal car behavior. Those are briefly summarized below. 
Persistence of bimodality varied a lot. Even for a well established firm bimodal car could remain sometimes only one day. IN those short bimodality cases the disclosed news in those reports were not very radical. Bimodal effects were due to simultaneous effect of positive and negative news.

Very persistent bimodalities (whole investigation window, 11 days) were also realized. Permanent bimodality was mainly due to the information regarding the market situation as a whole. Operations in order to handle the difficult situation or new phase of the company was interpreted as a favorable news by the markets.

Bimodality for well established, widely known firms usually started from the beginning of the examination window and stayed some days. After that the bimodality disappears. This finding support the view that active analysts can benefit from the disappearing of bimodality if they will react rapidly enough to the favorable and unfavorable news disclosed in interim reports.

Finally it should be mentioned that economic recession times, such as in 1989 and 1990, increased the frequency of bimodal returns through several industries. In 1990s the bimodality was more common phenomenon than in 1980s.

To conclude, we analyzed interim reports to show the type of new information that creates bimodal cars. Thus, application of the findings can be immediately applied, though not with the precision desired. Our findings could help also reporting managers improve their efforts to communicate value determining information to the markets Subsequent research must be relied upon for more detailed insight about information causing bimodality, but this article is a beginning place.

Appendix - Example of conflicting information [abbreviation for a firm in brackets]

For each one of these firms, we have: (1) the industry in which it operates, (2) favorable indicator(s), and (3) unfavorable indicator(s).

1) Effoa (Effjohn) [Effo] - 8 month interim report: Jan-Aug 1990.

Industry - Transport

Favorable indicator(s) - The number of passengers has increased and is expected to increase in the future. The January-August 1990 interim report discloses the merger of Effoa and Johnson Lines. [Previous literature indicates that the merger of firms with overlapping businesses should be favored by its shareholders (Healy, Palepu \& Ruback, 1992)].

Unfavorable indicator(s) - A large portion of its income comes from personal traffic. The economic recession in Finland causes people to reduce their spending on leisure traveling. The interim report explicitly mentions overcapacity available on the market. Yet, the firm is waiting for a new, large capacity vessel to be ready for its route.

2) Finnair [Fair] - 6 month interim report: Apr-Sep 1992.

Industry - Transport

Favorable indicator(s) - A program to reduce costs has been established.

Unfavorable indicator(s) - A large loss is recorded, due to weak Finnish Markka. Several negative changes in the operations regime: (1) a decrease in domestic demand, (2) a severe drop in the demand for charter flights, (3) excess capacity in the hotel business. 
3) Finnlines [Flin] - 8 month interim report: Jan-Aug 1993.

Industry - Transport

Favorable indicator(s) - Finnlines reports a large increase in earnings. The firm's long-run investment program is proceeding as planned.

Unfavorable indicator(s) - There is a national increase in the imbalance between import and export sea freight. The domestic purchasing power has been weakened, causing reductions in imports.

4) Ford [Ford] - 8 month interim report: Jan-Aug 1988.

Industry - Trade

Favorable indicator(s) - Record year for the registration of personal cars in Finland.

Unfavorable indicator(s) - Ford reports a decrease in market share, due to increasing competition.

5) Kesko [Kesk] - 8 month interim report: Jan-Aug 1992.

Industry - Trade

Favorable indicator(s) - Kesko reports success in its cost control efforts.

Unfavorable indicator(s) - The firm reports a decrease in net sales in several business lines. There is an anticipation that earnings will be at the level of the previous year.

6) Kuusinen [Kuus] - 8 month interim report: Jan-Aug 1987.

Industry - Trade

Favorable indicator(s) - The firm anticipates that its operational results for the whole year will exceed the figures for the previous year.

Unfavorable indicator(s) - Kuusinen reports the expansion to new businesses with few facts explaining the actual actions to be taken.

7) Säkkiväline [Sakk] - 8 month interim report: Jan-Aug 1993.

Industry - Other services

Favorable indicator(s) - Säkkiväline's costs are in control. Despite the decrease in net sales, the net earnings figure is same as in the previous year for the same interim period.

Unfavorable indicator(s) - The general recession has influenced the areas in which Säkkiväline operates.

8) Starckjohann [Star] - 8 month interim report: Jan-Aug 1989.

Industry - Trade

Favorable indicator(s) - The firm reports an increase in sales by two means: (1) acquisitions and (2) growth in business operations.

Unfavorable indicator(s) - In the outlook section there is an explicit indication of the weakening of the business situation.

9) Stockmann [Stoc] - 6 month interim report: Jan-Jun 1993.

Industry - Trade

Favorable indicator(s) - Stockmann reports an increase in sales.

Unfavorable indicator(s) - There is an anticipation that the level of national consumption will further decrease. 
10) Tamro [Tamr] - 8 month interim report: Jan-Aug 1985.

Industry - Trade

Favorable indicator(s) - The firm reports an increase in sales in all business lines, despite the weakness in the Finnish consumer goods sector.

Unfavorable indicator(s) - Difficulties with the consumer goods sector remain.

11) Talousosakekauppa [Taok] - 8 month interim report: Jan-Aug 1989.

Industry - Trade

Favorable indicator(s) - Talousosakekauppa reports an increase in earnings.

Unfavorable indicator(s) - The firm reports: (1) a decline in sales and (2) the lay-off of 500 personnel.

12) Tietotehdas [Tiet] - 6 month interim report: Oct 1987-Mar 1988.

Industry - Other services

Favorable indicator(s) - Tietotehdas reports that it has acquired a majority in Datema. At that time, Datema is the largest data-service and data-programming firm in the Nordic countries. According to the interim report, Tietotehdas gaines a strong market position in Sweden as well as a foothold to Norway and Denmark through the acquisition.

Unfavorable indicator(s) - The future of computer business as a whole is uncertain at the time.

13) Amer [Amer] - 6 month interim report: Mar-Aug 1989.

Industry - Other industries

Favorable indicator(s) - Amer reports: (1) large mergers into new branches, (2) the expansion of brands into its product portfolio, and (3) the stock purchase of Wilson Sporting Goods Co. The acquisition of Wilson Sporting Goods makes the operations of the Amer Group global. The larger firm is also now more production oriented. Among other things, it is said that Wilson: (1) will be an important corner stone and (2) should help diversify risk. Amer expects a crucial extension toward leisure consumer goods.

Unfavorable indicator(s) - An economic recession, with bearish expectations for the Helsinki stock market, is old information the Amer group reports as background.

14) Asko [Asko] - 8 month interim report: Jan-Aug 1989.

Industry - Industry

Favorable indicator(s) - A significant increase in sales, with a stable level of profitability, is reported by Asko.

Unfavorable indicator(s) - Asko anticipates that economic recession could decrease the firm's results for the whole year.

15) Enso-Gutzeit [Enso] - 8 month interim report: Jan-Aug 1991

Industry - Forest industry

Favorable indicator(s) - A wide-ranging program of efficiency and cost-cutting measures has been introduced to try to restore profitability.

Unfavorable indicator(s) - There are no expectations for the market to recover in the near future. This means the financial results for forest industry companies will be poor.

16) Finvest [Finv] - 6 month interim report: Jan-Jun 1993.

Industry - Other industries

Favorable indicator(s) - Finvest report a a decrease in loss, compared to previous year.

Unfavorable indicator(s) - The firm reports continuing negative earnings, and heterogeneity in the market situation. 
17) Huhtamäki [Huht] - 8 month interim report: Jan-Aug 1992.

Industry - Multi-business

Favorable indicator(s) - Huhtamäki reports a strong increase in both sales and earnings.

Unfavorable indicator(s) - A slow-down in the firm's development, because of the slow economic development in Finland and the increase in financial costs, due to the devaluation of the Markka.

$$
\text { Instrumentarium [Inst] - } 8 \text { month interim report: Jan-Aug } 1986 .
$$

Industry - Industry

Favorable indicator(s) - The firm reports that a share issue is successful. In addition, the sales for both patient monitors and professional kitchen equipment is increasing.

Unfavorable indicator(s) - Instrumentarium's export of hospital equipment to the Soviet Union has dropped to onethird of the previous year's export level. Sales within Finland and exports to other countries have not increased sufficiently to cover the loss in sales to the USSR.

19) Kajaani [Kaja] - 8 month interim report: Jan-Aug 1986

Industry - Forest industry

Favorable indicator(s) - Kajaani reports an increase in earnings. The increase is especially due to better productivity.

Unfavorable indicator(s) - Increased paper supply in the markets, causing potential production restrictions during the end portion of the year, are reported.

20) Kone [Kone] - 8 month interim report: Jan-Aug 1989.

Industry - Metal and engineering

Favorable indicator(s) - Kone has experienced: (1) an increase in sales and (2) a doubling of earnings, compared to the previous year.

Unfavorable indicator(s) - Demand in some areas is slowing down.

21) Kymi-Strömberg [Kyst] - 8 month interim report: Jan-Aug 1992.

Industry - Forest industry

Favorable indicator(s) - Devaluation strengthens Kymi-Strömberg's possibilities to deliver overseas. Actions for cost reduction and operational efficiency are proceeding as planned.

Unfavorable indicator(s) - Due to a large production portfolio, the recession in the pulp and paper industry is explained to hit the firm hard.

22) Lassila \& Tikanoja [Lass] - 8 month interim report: Jan-Aug 1993.

Industry - Other services

Favorable indicator(s) - Technically, the firm's exceptional investment project has been successful.

Unfavorable indicator(s) - Practically, Lassila \& Tikanoja has experienced a decrease in earnings. One business line is performing worse than in the previous year.

23) Leo-Longlife [Leol] - 6 month interim report: Apr-Sep 1993.

Industry - Other industries

Favorable indicator(s) - All income statement figures show increases. The firm's market prospects are improving.

Unfavorable indicator(s) - Current and anticipated profitability is indicated to be only satisfactory. 
24) Liha-Polar [Lihp] - 6 month interim report: Jan-Jun 1989.

Industry - Food industry

Favorable indicator(s) - Liha-Polar reports an increase in both sales and earnings, compared to the previous year.

Unfavorable indicator(s) - The total meat production in Finland has decreased.

25) Lohja [Lohj] - 6 month interim report: Mar-Aug 1990.

Industry - Multi-business

Favorable indicator(s) - Merger between Lohja and Wärtsilä is reported.

Unfavorable indicator(s) - The merger yields a: (1) mixed development of business lines, (2) tight financial situation during the whole reporting period.

26) Mancon [Manc] - 8 month interim report: Apr-Nov 1985.

Industry - Industry

Favorable indicator(s) - Mancon is active in buying firms and develop them.

Unfavorable indicator(s) - The size of the current organization is too large. There is a need for a complete restructuring of the present organization.

27) Metra [Metr] - 6 month interim report: Mar-Aug 1991.

Industry - Multi-business

Favorable indicator(s) - In certain cases, the profitability in those divisions with a more international presence actually exceeded targets. International objectives were met last year.

Unfavorable indicator(s) - "When the Metra Group was planning its operations for the current year, there were clear signs of a slump in demand in the main markets. However, the recession has turned out to be far more severe than expected, particularly in Finland, and the outlook is fraught with a number of unpredictable factors." And "The Metra Group failed to achieve its sales and profit targets during the review period. The largest shortfalls were experienced in the divisions most dependent on Finland and the other Nordic countries."

28) Metsä-Serla [Mets] - 8 month interim report: Jan-Aug 1993.

Industry - Forest industry

Favorable indicator(s) - Results for the second quarter are positive and exceed the budgeted figures.

Unfavorable indicator(s) - The increase in demand is forecasted to be slowing.

29) Nokia [Noki] - 8 month interim report: Jan-Aug 1991.

Industry - Telecommunication and electronics

Favorable indicator(s) - Nokia's finance structure, due to some share sales, is stronger, compared to the previous year.

Unfavorable indicator(s) - There are great uncertainties in major market areas. Exports to Russia are almost zero.

Otava [Otav] - 8 month interim report: Jan-Aug 1987.

Industry - Media and publishing

Favorable indicator(s) - Otava reports: (1) an increase in the operating profits, and (2) improved operational efficiency.

Unfavorable indicator(s) - The firm reports a drop in sales volume. 
31) Outokumpu [Outo] - 4 month interim report: Jan-Apr 1991.

Industry - Metal and engineering

Favorable indicator(s) - The results of the steel segment have been satisfactory.

Unfavorable indicator(s) - The results of all other segments have been unsatisfactory.

32) Partek [Part] - 8 month interim report: Jan-Aug 1993.

Industry - Multi-business

Favorable indicator(s) - Partek reports prospects for improved operational results during the rest of the year.

Unfavorable indicator(s) - The recession is expected to continue in the European market area during 1994.

33) Polar [Pola] - 8 month interim report: Jan-Aug 1993.

Industry - Other industries

Favorable indicator(s) - Polar's restructuring program, covering the whole firm, has been started.

Unfavorable indicator(s) - Prospects for the building business are weak.

34) Raision Margariini [Raim] - 6 month interim report: Jan-Jun 1993.

Industry - Other industries

Favorable indicator(s) - Improved sales and earnings are both reported.

Unfavorable indicator(s) - The performance for the second half of the year is expected to be worse than during the first half.

35) Raision Tehtaat [Rait] - 6 month interim report: Jan-Jun 1990.

Industry - Other industries

Favorable indicator(s) - Prospects for favorable earnings development for the rest of the year are reported.

Unfavorable indicator(s) - Raision Tehtaat reports a severe drop in earnings, compared to previous year.

36) Rauma-Repola [Raum] - 8 month interim report interim reports(s): Jan-Aug 1987.

Industry - Industry

Favorable indicator(s) -Profitability for the paper industry is still good.

Unfavorable indicator(s) - Profitability for the metal industry, with few exceptions, is behind the target. Negative earnings in the metals segment are reported.

37) Rautaruukki [Raut] - 8 month interim report: Jan-Aug 1992.

Industry - Metal and engineering

Favorable indicator(s) - Rautaruukki reports an improvement in operating profits. The market situation in Finland could be better at the beginning of 1993 .

Unfavorable indicator(s) - More uncertainties to be faced in the European markets are anticipated.

Repola [Repo] - 8 month interim report: Jan-Aug 1993.

Industry - Industry

Favorable indicator(s) - There is a noticeable improvement in earnings. Prospects for continuing improvement for profitability are reported. Good demand in North America and Asia are believed to continue.

Unfavorable indicator(s) - Demand in Western Europe is supposed to continue to be low. 
39) Rosenlew [Rose] - 8 month interim report: Jan-Aug 1985.

Industry - Industry

Favorable indicator(s) - Rosenlew reports improved earnings for the period and anticipates the improvement to continue the rest of the year.

Unfavorable indicator(s) - The forest industry sector is behind the budget. Balance of trade problems with the Soviet Union persist.

40) Schaumann [Scha] - 8 month interim report: Jan-Aug 1987.

Industry - Forest industry

Favorable indicator(s) - The firm reports record pulp production, with corresponding increased earnings.

Unfavorable indicator(s) - The success in the pulp and paper segment does not totally compensate for the loss in plain and saw sector.

41) Spontel [Spot] - 8 month interim report: Jan-Aug 1987.

Industry - Industry

Favorable indicator(s) - Results for all four of Spontel's business lines are above targets.

Unfavorable indicator(s) - The prospects for one of the business lines, the liquidity management company, are difficult to forecast.

42) Tamfelt [Tamf] - 8 month interim report: Jan-Aug 1993.

Industry - Other industries

Favorable indicator(s) - Tamfelt reports: (1) growth in sales, compared to previous year, (2) an increase in exports, (3) an increase in orders, and (2) a backlog in orders.

Unfavorable indicator(s) - The firm reports a decrease in sales in Finland. In addition, the firm is experiencing an underutilization of capacity.

43) Tampella [Tamp] - 8 month interim report: Jan-Aug 1988.

Industry - Other industries

Favorable indicator(s) - A large investment program was launched. Furthermore, the overall development and future prospects of business lines are favorable. There is also a column indicating Tampella's strong initiative to internationalize its operations via acquisitions.

Unfavorable indicator(s) - Prices in the cardboard industry are unsatisfactory.

44) Suomen Trikoo [Trik] - 6 month interim report: Jan-Jun 1988.

Industry - Other industries

Favorable indicator(s) - New cooperation activities in Sweden and in Estonia are reported.

Unfavorable indicator(s) - A decrease in the earnings for the parent company is reported.

45) Valmet [Valm] - 8 month interim report: Jan-Aug 1993.

Industry - Metal and engineering

Favorable indicator(s) - Improvements in overall performance are reported by Valmet.

Unfavorable indicator(s) - One business line continues to produce losses. 
46) Virke [Virk] - 8 month interim report: Jan-Aug 1989

Industry - Industry

Favorable indicator(s) - Virke reports an overall improvement in its income statement figures.

Unfavorable indicator(s) - Uncertainties regarding the exports to Russia are reported.

47) Wärtsilä [Wart] - 4 month interim report: Jan-Apr 1990

Industry - Metal and engineering

Favorable indicator(s) - The increase of net sales has been strong. This development has been accelerated due to newly merged companies. All the industry-lines report superior results, compared to the previous year (Jan-Apr, 1989).

Unfavorable indicator(s) - The former administration of Wärtsilä has been sued by shareholders, who are seeking to receive compensation related to: (1) share issues and (2) order backlog transfers. Further, Wärtsilä has large contracts with the Soviet Union to supply new icebreakers. The collapse of the USSR causes the interim reports to present very unfavorable prospects for the firm.

48) WSOY [Wsoy] - 8 month interim report: Jan-Aug 1990.

Industry - Media and publishing

Favorable indicator(s) - WSOY reports: (1) an increase in sales, and (2) a stable financial position.

Unfavorable indicator(s) - The firm reports the anticipation of a slight decrease in the profitability of operations.

\section{References}

1. Healy P. M., \& Palepu, K. G. (2001). Information asymmetry, corporate disclosure, and the capital markets: A review of the empirical disclosure literature. Journal of Accounting and Economics, 31: 405440.

2. HSE Cooperative (1988). The articles, rules and regulations of the Helsinki Stock Exchange. Helsinki: Multiprint.

3. Kahra, H. A., Kanto, A. J., Schadewitz, H. J., \& Blevins, D. R.. 2001 Bimodal security market residuals, The International Business and Economics Research Conference: Program and Proceedings (October) CD File No. 235.

4. 2004. Anatomy of interim disclosures during bimodal return distributions. Under review.

5. Kanto , A. J., Kahra, H. A., Blevins, D. R., \& Schadewitz, H. J. (1998). An explanation of the unusual behavior of some market model residuals. The Finnish Journal of Business Economics, 47: 288-300.

6. Kothari, S. P. (2001). Capital markets research in accounting. Journal of Accounting and Economics, 31: 105-231.

7. Schadewitz, H. J, \& Kanto, A. J. (2002). The impact of disclosure on the market response to reported earnings. Scandinavian Journal of Management, 18: 521-542. 